\title{
A plástica escénica na Galicia do século XXI
}

\author{
Galician Stage Design in the 21st Century
}

\author{
Diego González VALEIRAS
}

Escola Superior de Arte Dramática

dgvaleiras@gmail.com

[recibido 28/10/2014, aceptado 09/02/2015]

\begin{abstract}
Na arte, non no simulacro artístico, o artista verte o seu espirito no traballo e non ten por que se preocupar do problema da nacionalidade da súa obra que, pola contra, é, como obra artística, universal, pois a nacionalidade, a particularidade, xurde das coincidencias espirituais, da comunidade de gostos e sentimentos coas xentes dos seu pobo. Na maneira instintiva do artista de empregar os medios de expresión, descóbrense ás veces os caracteres comúns dunha nacionalidade.
\end{abstract}

(Seoane, 1994: 25)

\section{RESUMO}

O presente artigo ten por obxecto realizar unha panorámica analítica do deseño escenográfico galego nos primeiros anos do século XXI e a relación que se establece tanto cos antecedentes como entre as diferentes montaxes teatrais. Atenderase ao traballo dos artistas xa consagrados cun corte máis clásico fronte ás rupturas estéticas e formais dos novos creadores, e como estas axudan na renovación da plástica escénica e a súa relación cos públicos.

PALABRAS CHAVE: Plástica escénica, teatro galego, artes escénicas contemporáneas, escenógrafos.

\section{RESUMEN}

El presente artículo tiene por objeto realizar una panorámica analítica del diseño escenográfico gallego en los primeros años del siglo XXI y la relación que se establece tanto con los antecedentes como entre los diferentes montajes teatrales. Se atenderá al trabajo de los artistas ya consagrados con un corte más clásico frente a las rupturas estéticas y formales de los nuevos creadores, y cómo estas ayudan en la renovación de la plástica escénica y su relación con los públicos.

PALABRAS CLAVE: Plástica escénica, teatro gallego, artes escénicas contemporáneas, escenógrafos.

\begin{abstract}
This article aims to make an analytic overview of the Galician stage design in the early twenty-first century and the relationship established both with the past as with different theatrical productions. The work of renown artists with a more classical style will be compared to the aesthetic and formal changes of new creators and how the later help the renovation of scenic modeling and its relationship with the public.
\end{abstract}

KEY WORDS: Stage design, Galician theatre, contemporary performing arts, scenographers.

GonZÁlez Valeiras, D. (2015): “A plástica escénica na Galicia do século XXI”, Madrygal (Madr.), 18, Núm. Especial: 569-577.

SUMARIO: 1. Breve introdución histórica á arte escenográfica galega. Os antecedentes rexionalistas. 2. O teatro independente en Galicia, reflexos escenográficos. 3. O nacemento do teatro público na era autonómica e as consecuencias para o oficio escenográfico. 4. A produción escénica contemporánea, escenografía entre a fin e o novo milenio. 5. Os referentes escenográficos da escena galega actual. Algunhas conclusións. 6. Referencias bibliográficas. 
1. BREVE INTRODUCIÓN HISTÓRICA Á ARTE ESCENOGRÁFICA GALEGA. OS ANTECEDENTES REXIONALISTAS

Queremos comezar con esta cita de Luís Seoane (1910-1979), un dos grandes referentes plásticos e renovadores culturais da arte galega, nado nun fogar de emigrantes en 1910 na Arxentina, porque esta idea de identidade na arte ben pode axudarnos a reflexionar sobre a súa aplicación na arte escenográfica e a evolución dende o teatro rexionalista ${ }^{1}$ até os días de hoxe. Con este artigo pretendemos facer unha análise diacrónica sobre a evolución da imaxe escénica ao tempo que a poñemos en relación coas principais tendencias e innovacións a nivel internacional. Deste xeito, remataremos sinalando aqueles creadores que hoxe forman parte da referencia e do canon estético da produción teatral, e se dalgún xeito podemos establecer certos trazos distintivos no corpus escenográfico galego do novo milenio.

Xunto a Luís Seoane, podemos conformar unha serie de grandes nomes da arte galega que comezan unha tardía, historicamente falando, pero precursora actividade escenográfica na realidade teatral galega. Poderemos ver precisamente a perdurabilidade das grandes tendencias na escenografía galega durante moitos anos en persoas como Camilo Díaz Baliño, na creación dos panos pintados, coma Donosiña ou $A$ man da santiña para o Conservatorio Nazonal do Arte Galego (1919) a partir dun texto de Ramón Cabanillas, ou no deseño do espazo escénico d'O Mariscal, onde quizais demostrou unha maior conexión coa renovación escenográfica europea achegada polo suízo Adolphe Appia, para quen a plástica escénica ten como principio fundamental suxerir en maior medida ca ilustrar. Así nolo amosan nos seus respectivos estudos Euloxio Ruibal (2003) e Roberto Pascual (2007).

Tamén debemos reparar na destacada obra de Castelao, a quen se consideraba pola crítica da época o maior representante "cubista" e "ultraísta" galego (Vieites 2007) nalgunha das súas propostas, aínda que mantendo -como podemos ver en Divinas Palabras de Valle Inclán ou na escenificación do seu propio texto Os vellos non deben de namorarse para a Sociedad Coral Polifónica de Pontevedra (19261930) - aspectos máis populares propios da mestura do ideal que un teatro de arte nacional persegue e cuxa convivencia máis ou menos harmónica perdurará ata a modernización e o debate das postas en escena de Abrente (Ribadavia, 1973-1980).

Non debemos esquecer que a escena galega, conectada en varios momentos da historia coa vangarda e a modernización (agás en reximes de letargo enxebrista e folclorizante para a arte supervivente en galego en momentos hostís e impermeables como o franquismo), tamén buscou a súa propia transgresión e estilización identitaria. Podemos, neste senso, pensar en momentos coma o do realismonaturalismo na escena renovadora do palco dos teatros de Europa. Na súa traslación á cultura galega, falaremos por caso da estrea (primeira representación de teatro en galego da que se ten constancia; Vieites 2007) no Liceo Brigantino da Coruña da peza $A$ fonte do xuramento (1882), a partir do texto de Francisco María de la Iglesia, onde se ben a plástica escénica toma como referentes a realidade circundante mediante o uso de obxectos como as armas de fogo confiscadas pola Garda Civil na zona ou pezas de vestuario do cotián das xentes do lugar procuradas en Mera, na parroquia de Maianca (lugar onde trascorre a acción

\footnotetext{
${ }^{1}$ Movemento socio-político-cultural que trata, mediante a expresión plástica, defender e ensalzar as peculiaridades e particularidades dunha rexión ou comunidade tomando como referentes a arquitectura tradicional, a indumentaria e a forma de vida.

${ }^{2}$ Movemento estético, especialmente o literario e particularmente o poético, que se produce en España e Iberoamérica na segunda década do século XX tentando recoller e unificar as tendencias vangardistas mundiais do momento.
} 
da ficción), tamén se pode ver na didascalia inicial do propio texto un convite a esa transgresión estilizante:

Anque n-a parroquia onde ten lugar esta aución, así como en todál as d'a Veiramar, é moi raro ver hoxe, n'o dia de festa, un solo mozo vestido de calzón e monteira, nin unha rapaza con dengue (o que é ben de lamentar) conviría que n'a concurrencia á parroquia, e á foliada d'o Santo, con que esconenza o auto segundo, aparecesen varias parellas co-el; así coma tamén outras con cirolas, polainas... (Lourenzo e Pillado 1982: 42)

\section{O TEATRO INDEPENDENTE EN GALICIA, REFLEXOS ESCENOGRÁ- FICOS}

Noutros momentos, como as Mostras de Ribadavia, onde conflúen ideoloxías e persoas de toda Galicia que procuran nos debates un ámbito de libre expresión e transgresión, tamén de dignificación de certos valores culturais autónomos e parateatrais (como a estética do entroido) mesturándoos coas tendencias máis vangardistas, comeza a profunda reflexión do futuro do teatro galego e de cal debería ser o seu camiño, ademais da súa concreción a nivel de construción e deseño escenográfico. Por unha banda, nesta época, existe un sector máis tradicionalista e apegado ao realismo, onde as formas deben continuar pola liña deixada polos precursores Baliño, Castelao e Lugrís, onde en moitas das súas escenografías e panos de boca e fondo se retrata a Galicia idealizada, un arquetipo de país adornado cos elementos simbólicos e imaxes iconográficas da propia cultura, a paisaxe ou a arquitectura con "todo o colorido da verdade e con todo o realismo da exactitude", como nos recomendaba Lugrís Freire (Vieites 2006).

Velaquí un retrato que conectará precisamente cun dos maiores defensores da corrente popular do noso teatro no movemento do teatro independente galego de Abrente, Eduardo Blanco Amor, quen considera que debe ofrecérselle ao público algo entendible e acorde co seu (re)coñecemento cultural. Pola outra banda, e acusados por persoeiros da literatura galega, como o propio Eduardo Blanco Amor, de "generación universitaria, intelectualizada y pequeño burguesa (...) muchachos desprovistos de tradición que no conocían a Castelao ni a Risco, imitan lo que tienen más cerca, Europa" (López Silva e Vilavedra 2002), teremos a homes de teatro total, que combinan as súas facetas de dramaturgo, actor, director ou escenógrafo, coma Roberto Vidal Bolaño ou Manuel Lourenzo.

Aparece un novo grupo de artistas que entenderán que era hora de loitar, xa desde a permeabilidade democrática e morto o ditador, por un ámbito de experimentación e investigación, onde ter presentes as diferentes correntes e estéticas culturais, como foi o posicionamento, entre outros, de Euloxio Ruibal: “...sen un exhautivo coñecemento do teatro avangardista doutras latitudes dificilmente se poderá caminar i esperimentar cara un teatro propiamente galego de calidade estética, un teatro que exprese e comunique eticamente a nosa problemática” (López Silva e Vilavedra 2002).

Desas diverxencias creadas en torno ás Mostras de Ribadavia, nacerán as ideas que asentarían a necesidade dun teatro institucional, unha idea que xa se apuntaba nas primeiras tentativas dun Teatro Nacional a principios de século e que se conformaban ao redor do Movemento Dramático Nacional, o Conservatorio Nazonal do Arte Galego ou a Escola Dramática Galega. Trala restauración da democracia comezan a formalizarse e asentarse compañías de teatro formadas polos novos talentos xurdidos de Ribadavia, talentos como Roberto Vidal Bolaño, grande expoñente escénico-artístico galego, xa que o seu papel non se limitou á dirección ou á escrita, senón que botou man da escenografía, a iluminación e a interpretación, creando así o mapa dos oficios do teatro, onde as diferentes disciplinas cohabitaban en simbiose na figura do artista total, produtor e empresario (Pascual 2013). Tamén aparece de novo a necesidade da creación dunha escola superior que forme artistas escénicos en Galicia, comezando así un longo proceso de normalización que a día de hoxe non parece semellar rematado, senón que dá duros sinais de retroceso baixo a sombra dunha crise no ámbito cultural que non sabemos se non se pode ou non se quere rematar. 
3. O NACEMENTO DO TEATRO PÚBLICO NA ERA AUTONÓMICA E AS CONSECUENCIAS PARA O OFICIO ESCENOGRÁFICO

No ano 1984 bota a andar o Centro Dramático Galego (CDG). Co propósito de levar a escena clásicos galegos e universais, xunto coa nova dramaturxia, comezan as montaxes que no ano 2000 acadan xa as 56 escenificacións e 29 máis ata o día de hoxe, o que nos ilustra claramente a freada contundente na produción escénica da compañía pública, sobre todo no último período de crise económica mundial e dos recortes públicos na cultura. Tanto as compañías privadas como a institucional amosan certa tendencia á procura do tempo perdido, feito este que marcará moito a traxectoria do CDG, que semella querer condensar en vinte anos todo un proceso artístico que vai dende as primeiras vangardas ata a revolución de Abrente. A primera peza, Woyzeck de Brüchner, camiña no espectro estético marcado nalgunha das pezas creadas por Vidal Bolaño como o Laudamuco señor de Ningures (1977), un expresionismo tardío que se mestura co populoso fervor de identidade dos 80. A escenografía está deseñada por Paco Conesa, proposta caracterizada polo uso de plataformas de madeira para a creación de diferentes nives con vestiario de formas simples e monocromáticas. Conesa, un habitual da compañía institucional, estará presente ao longo da súa historia en máis de dez montaxes con achegas escenográficas moi diversas pero cun nexo común, a estilización das formas e a búsqueda no vestiario dun realismo histórico que deixa poucas licenzas á imaxinación.

Xunto a el tamén outros escenógrafos como Rodrigo Roel, co que quizais se estilizan aínda máis as formas e se busca a creación simbólica a través dos espazos metonímicos, grandes elementos verticais ou horizontais que pola súa textura e cor nos entregan información suficiente para nós crear a imaxe do que falta; ou Suso Montero, creador que se move no mundo dos materiais alternativos, plástico, cartón, etc., da estética do audiovisual (abundante uso de bastidores) cun traballo plástico que selecciona novos materiais e uso de cores primarias; aínda que tamén houbo cabida para escenógrafos como Carlos Alonso, apaixoado da regras das tres r's (reciclar, reutilizar, reusar $^{3}$ ), configurándose como artista ecléctico onde as potencialidades do xa usado son postas en escena baixo novos valores estéticos e funcionais. Todos eles compaxinaron o traballo de forma externa para outras compañías e con intervencións no CDG.

Abrindo o mileno (xaneiro de 2000) estréase no Salón Teatro, sede do CDG, Os vellos non deben de namorarse de Castelao, con vestuario, atrezzo e ambientación de R. Roel, retomando as liñas dunha estética costumista. Non nos atrevemos a establecer unha clara liña estética nas montaxes da compañía, xa que o eclecticismo e a diversidade temática e de cosmovisión non atende a unha liña demasiado definida nesta época, observando así propostas moi variadas que saltan de $A$ burla do galo (2000) de Vidal Bolaño, onde un espazo minimalista se habita de personaxes decimonónicos, a unha creación escénica para o Calígula (2000) de A. Camus, que viaxa polas plataformas e escaleiras de Craig e Appia. Do salto de A cacatúa verde (2001) de Arthur Schnitzler, cunha clara proposta realista ambientada no século XVIII, á vangarda estética de Baltasar Patiño co seu minimalismo simbólico nos materiais utilizados e combinados, por exemplo, co inspirador vestiario de Carlos Alonso, creado baixo a súa agulla de estética collage en $O$ ano do cometa (2004) de Álvaro Cunqueiro, baixo a dirección de Quico Cadaval. É esta unha adaptación escénica presidida na plástica pola atmosfera metálica do ferro

\footnotetext{
${ }^{3}$ Neste contexto, a diferenza entre reutilizar e reusar radica en que, no primeiro caso, falamos de elementos que cobran unha función distinta na escena á que foron orixinalmente concibidos. No segundo caso, falamos deses obxectos xa introducidos no ámbito diexético que o artista volve empregar readaptándoos ou recolocándoos, con certa autorreferencialidade, en distintos espectáculos.
} 
e aluminio utilizado en grandes paneis traslúcidos e móbiles, usados para a creación de espazos que no primeiro termo atopará unha plataforma cunha cidade reducida a modo simbólico e que contrasta polo tamaño co resto da escenografía.

Nos últimos anos da primeira década deste século XXI, o CDG viviu ao noso entender unha renovación estética que se facilitaba tamén coa toma de contacto con autores contemporáneos como Bernard-Marie Koltès na montaxe $O$ regreso ao deserto, dirixida por Cristina Domínguez (2006) e con espazo escénico de Xoán Anleo, onde as formas se tornaban en sinxelas estruturas móviles con rodas. Un espazo minimalista lonxe das grandes (re) creacións escenográficas creado en base a catro cubos ocos que establecían os diferentes espazos da ficción: casa, bar, patio, muro, etc. Logo do paso de grandes producións como Noite de Reis, de W. Shakespeare, dirixida por Quico Cadaval e con espazo escénico de B. Patiño (2007), ou A piragua (2007), texto e dirección de Cándido Pazó coa escenografía e vestiario de Carlos Alonso - unha escenografía que habería de se reinventar anos despois cando Abrapalabra (2009) a retoma dándolle un carácter máis recoñecible da estética de Alonso na acumulación de obxectos--, esta prolífica etapa remata coa posta en escena de As actas escuras de Vidal Bolaño, coa batuta de Xulio Lago (2010) e con espazo escénico novamente de Roel. Neste deseño, a través de grandes bastidores configúrase, con movementos xiratorios, a recreación e o áxil tránsito das diferentes estancias que van desde o interior da catedral de Santiago ata a estación de tren.

Superado este período, a compañía institucional comeza, na nosa opinión, un camiño de certo declive tanto na estética, como na propia calidade da confección dos espectáculos que se conseguen levar a cabo malia aos severos recortes no sector. Nesta nova etapa retómanse antigos éxitos onde se transgreden os límites da arte como en Salomé de Oscar Wilde, coa dirección de Carlos Santiago (2010), cunha evidente e pobre resolución escenográfica (unha carpa de mítin-comida política) que máis ben lembra a un teatro iniciático e afeccionado ca a unha compañía institucional. Asistimos tamén a reposicións onde, baixo o noso punto de vista, a reutilización do material escenográfico creado para montaxes anteriores deixa de lado a capacidade creadora do escenógrafo como impulsor da autonomía da obra escénica. É o caso da proposta de $O$ profesional de Dusan Kovacevic, baixo a dirección de Manuel Guede (2012), onde as estruturas creadas por un arquitecto (estantes baleiros para libros que funcionan a modo de porta-parede) para unha montaxe no país veciño (Portugal) se reutilizan sen unha clara razón estética, funcional ou densidade dramatúrxica.

Da escasa produción dos últimos anos, destacamos deste CDG freado e aletargado a principal produción coa que a compañía homenaxeou o autor das Letras Galegas, o primeiro integramente teatral, Roberto Vidal Bolaño. Presentouse, daquela, Días sen Gloria, guiada por Fefa Noia, con escenografía de Patiño, un espazo aséptico e transformable, que segundo o autor busca que sexa unha "selva" que se abre e se pecha, un espazo que ao noso ver non busca a especificidade coa peza escrita e que ben se pode empregar para outros textos. Neste sentido, como afirmou a crítica, falta na resolución a sucidade ou escuridade propia deste texto dramático que vai máis alá da movie road ou da multiespacialidade do Camiño de Santiago, esa mesma sucidade que se botaba de menos no pulcro universo de prostitución e delincuencia de Mackie en $A$ ópera dos tres reás (2011), de Brecht, con autoría escenográfica tamén de Patiño (Xestoso, 2011).

\section{A PRODUCIÓN ESCÉNICA CON- TEMPORÁNEA, ESCENOGRAFÍA EN- TRE A FIN E O NOVO MILENIO}

Pasamos agora á produción privada, que nos últimos anos asiste á aparición de novas propostas estéticas e escénicas maioritariamente de pequeno formato, fronte á magoada desaparición doutras que foron e serán sempre referentes. A renovación é a saída que moitas das compañías adoptan fronte aos tempos incertos que vivimos e así o fan formacións como Matarile Teatro, que coas súas formas estéticas achegaron a visión contemporánea do teatro-danza a Galicia; o grupo Chévere, 
que a través das súas propostas que rozan o teatro documento axitan os públicos, ou Sarabela Teatro, que conseguiu crear unha estética propia baseada en pezas cun pouso surrealista, entre outras compañías superviventes.

Tomemos agora o estilo da compañía Voadora, dirixida por Marta Pazos. Nos seus espectáculos apreciamos unha nova liña no teatro galego, non antes sen establecer pontes estéticas con correntes Pop, Indie ou Punk. Pazos, con esta estética bebe das experiencias do manexo dos materiais e as súas posibilidades. A partir do traballo de experimentación interartística vai incorporando e adaptando ao conxunto novos elementos, como o uso de cortiza no chan, creando texturas e volumes que se transforman, sen realismos. Na súa última montaxe A tempestade (2014), de W. Shakespeare, preséntanos un espazo libre de escenografía (obra neste caso de Ana Luena), cunha sorte de entarimado lonxitudinal na parte posterior do escenario que se vai enchendo de atrezzo a medida que se suceden as escenas. Elementos que se mesturan coa proposta metateatral da mesa do director de escena (Próspero), presente dende o inicio e remarcada por unha lámpada de mesa. Pazos acostuma espir o escenario, gusta da arquitectura teatral (xa Patiño nos amosara a parede á vista da chácena ou o uso de elementos da infraestrutura do teatro como a composición do espazo escénico) e aposta por crear mundos oníricos, surrealistas e canallas, como apreciamos nesta última montaxe. A súa plástica vén de encher un espazo que estaba dominado polas vellas formas e a racionalidade dos materiais, con escasas concesións á multuplicidade de significados que os propios materiais poden conter.

Outro caso é o de Sarabela, do que xa comentabamos anteriormente o apoio determinante que a compañía ourensá ten no surrealismo estético, que podemos observar en montaxes como Cama 2 por 2 para 2 (1995) de Belbel, en Caricias (2004) do memo autor ou n'A Esmorga (1996 e 2009) de Eduardo Blanco Amor, nas súas dúas versións realizadas pola compañía. Neste apartado botamos a ollada cara á man creadora destes espazos oníricos de Suso Díaz, pois con el chegaron as propostas escenográficas, entre outras, de
Así que pasen cinco anos (2003) de Lorca ou Margar no pazo do tempo (2007), texto de Ánxeles Cuña. Díaz procura o uso de materiais e formas novas, gusta da texturización dos elementos mediante pinturas e acabados plásticos ou metálicos, como é o caso da última montaxe d'A Esmorga, ou do que xa se converteu nun dos sinais estéticos identificativos deste escenógrafo, as proxeccións abstractas como complemento escenográfico e atmosférico que ulilizará case en todas as súas montaxes posteriores, pero que toma especial relevancia na peza Margar no pazo do tempo. Unha liña escenoestética que se verá truncada coa súa prematura morte no ano 2010.

Continuamos agora con outro dos exemplos escénicos que ben amosan o camiño que a escenografía vén de tomar no último terzo do século XX e comezos do XXI. Matarile teatro e as propostas escenográficas de Baltasar Patiño. Como vimos anteriormente, Patiño é escenógrafo e iluminador tanto para as montaxes da súa compañía, Matarile, como nas colaboracións con outras entidades. Proporciona unha visión informalista da plástica, non procura espazos do común nin se pecha en propostas realistas; podemos dicir que prefire unha estética pop-rock, que por momentos se volve underground ou nun soño convertido en batalla, onde as cores saturadas e a sorpresa lumínica inundan a escena, coma nun cadro de Brueghel, na maior parte baleira, espida de panos e teas, nun exercicio grotesco de provocación directa.

Patiño responde, ata o de agora, ao perfil de artista investigador da luz, a cor, os aparellos e as formas e de como no seu tratamento se trasforman nun exercicio de colectividade e perspectiva para crear o espectáculo en cada espazo de exhibición.

Por outra banda temos a escenógrafos como Carlos Alonso que, como diciamos cando falamos do CDG, estrutura o seu poder plástico na reutilización dos materiais xa existentes para a creación de novas ideas estéticas ou ambientais. Amais de ser un excelente atrecista, Alonso pertence á categoría de artista plástico total. Nese parámetro, o da transformación do existente radica a base da súa metodoloxía 
de creación e ofrécenos resultados para espectáculos como a última montaxe do Grupo Chévere, O país dos ananos (2014), onde os bolsos se transforman en monteiras e mitras papais ou o mostrario de teas dunha tenda de retallos se volve un "cartón de peito" do de xogo infantil, nesta peza crea un gran pano onde colgan os vestiarios das montaxes da compañía, pois o espectáculo é un repaso pola historia da Galicia recente e polos quince anos de Ultranoites. Pero tamén é capaz de escapar do mundo da ensoñación e o maxín persoal e (re)crear un espazo realista, como para a montaxe As do peixe (2013) de Cándido Pazó, dirixida por Cristina Domínguez. Alonso trasládanos nesta ocasión a un espazo minimalista, onde os obxectos do cotián se volven útiles de escena, precisamente para a finalidade coa que foron creados, pero buscando a harmonía do conxunto. Así observamos unha sala de empaquetado de sardiñas dunha conserveira galega, un espazo recoñecible onde a indumentaria realista logra esa empatía directa co espectador.

Tamén cómpre destacar o papel que tivo Suso Montero no desenvolvemento da escenografía no teatro galego. Amante dos novos materiais como diciamos antes, Suso vai trasladar a súa tarefa escénica maiormente cara ao mundo do audiovisual, sobre todo coa eclosión da programación serial da TVG, que a finais do século XX encheu de éxitos a televisión autonómica. Con todo, non debemos esquecer o seu papel teatral, que ben se pode valorar a través de montaxes recentes como Viaxe a ningunha parte (2012). Na adaptación que Sarabela presenta do texto de Fernando Fernán Gómez, Montero lévanos cara ao mundo do pano de aparencias, nunha sorte de aparataxe escénica construída en madeira e tea que oculta os elementos de atrezzo, camas que saen das paredes, xunto a cadeiras e obxectos dos diversos espazos da ficción. Suso Montero séntese cómodo nos espazos non recoñecibles, gusta de crear universos paralelos coma no deseño de figurinos de Caderno de Bitácora (1985) do CDG, deixando que o plástico se apodere e confeccione o vestiario, marcado sen dúbida pola xeración dos oitenta e a explosión de cores e formas da "movida".

\section{OS REFERENTES ESCENOGRÁFI- COS DA ESCENA GALEGA ACTUAL. ALGUNHAS CONCLUSIÓNS}

Dos dezaoito anos que a Asociación de Actores e Actrices de Galicia leva organizando os premios de Teatro María Casares, quince das xerras foron parar ás mans dos citados artistas, se ben tamén destaca na historia da escenografía galega recente o traballo realizado por Antonio F. Simón, Pablo Giráldez "Pastor" ou Marcelino de Santiago "Kukas", entre outros. De todo o conxunto podemos obter un perfil estético que pensamos pode, de maneira xeral, amosarnos dúas grandes rutas no camiño que a plástica teatral está tomando en Galicia. Por unha banda temos, dende o noso punto de vista, os renovadores Marta Pazos, Baltasar Patiño, Suso Díaz ou mesmo Carlos Alonso e, pola outra, unha parte máis conservadora nas formas, configurada por Paco Conesa, Antonio Simón ou Suso Montero (se ben é certo que investigadores coma Santi Prego recoñecen que, este último, no seu momento, soubo "dar imaxe plástica a unha dramaturxia galega da posmodernidade, a través da utilización nos vestiarios de materiais ata o momento insólitos, como teas de paraugas ou goma espuma" (Vieites 2007: 350).

Malia a diversidade e abundancia de profesionais neste eido, a figura do escenógrafo é, en liñas xerais, a menos recoñecida popularmente, así como no nivel interno e externo do sistema teatral galego. A diferenza dos dramaturgos, directores ou actores e actrices, os escenógrafos non conseguiron aínda poñer de manifesto a relevancia da súa autoría, como si o lograron outros axentes do sistema. Aínda

\footnotetext{
${ }^{4}$ Elemento da indumentaria que, dende o século XVIII até comezos do XX, se empregaba para ocultar a fisonomía do corpo feminino.
} 
que nos últimos tempos o teatro galego tamén deu cabida á aparición da figura do directorescenógrafo $^{5}$ en espectáculos como Homes bisagra (Baltasar Patiño, 2014) ou a propia Marta Pazos, a autonomía e o concepto de autoría no ámbito plástico semella non obter un recoñecemento tan relevante ou inmediato coma o da interpretación, a dramaturxia ou a dirección. Tampouco coas grandes producións que ao longo da historia o teatro galego realizou, como Saxo tenor (Teatro do Aquí, 1993), Imperial, café cantante (Teatro do Noroeste, 2006), Glass City (Teatro do Noroeste, 2009), etc., a escenografía tivo oportunidade ou soubo recoñecer a estilística, o maxisterio ou as grandes obras con medios e recursos para a exploración na alta tecnificación ou en custosos recursos. Dificilmente poden darse casos de recoñecementos coma os que na actualidade teñen escenógrafos doutros contextos coma
Anna Viebrock ou Jan Pappelbaum, por poñer algúns exemplos do teatro alemán contemporáneo, se entre outros aspectos negativos o escenógrafo galego atopa a falta de recoñecemento artístico no baremo de axudas á produción de organismos públicos coma a AGADIC (Axencia Galega de Industrias Culturais).

Está por ver como influirá no actual panorama escenográfico a implantación en Galicia dos estudos de escenografía (en 2013 ve a luz a primeira promoción), de que maneira afronta o reto de combater a actual precariedade e pon en valor o que diciamos noutro contexto, que dende o noso punto de vista é fundamental tanto polas tendencias como pola evolución do oficio do escenógrafo, que debe "fixar a súa residencia na matriz creadora dos espectáculos e mesmo, ás veces, se converte no xermolo que concibe novas creacións artísticas".

\section{REFERENCIAS BIBLIOGRÁFICAS}

Centro Dramático Galego (2004): Centro Dramático Galego, 20 anos 1984-2004. Santiago de Compostela: IGAEM.

De Blas Gómez, Felisa (2009): El teatro como espacio. Barcelona: Fundación Caja de Arquitectos. DíAz, Xosé (ed.) (1994): Textos sobre Arte Galega e Deseño de Luís Seoane. Vigo: A Nosa Terra.

López SiLva, Inma e Dolores Vilavedra (2002): Un Abrente teatral. As Mostras e o Concurso de Teatro de Ribadavia. Vigo: Galaxia.

Lourenzo, Manuel e Francisco Pillado Mayor (1982): Antoloxía do teatro galego. Sada: Ediciós do Castro.

Pascual, Roberto (2007): “Camilo Díaz Baliño, escenas segadas”, Madrygal. Revista de Estudios Gallegos 10, pp. 165-169.

(2013): Roberto Vidal Bolaño e os oficios do teatro. Vigo: Xerais.

Ruibal, Euloxio (2003): “A arte escenográfica de Camilo Díaz Baliño”, Xogo de máscaras: escritos sobre teatro galego. A Coruña: Espiral Maior, pp. 9-17.

Seonne, Luís (1994): Textos sobre Arte Galega e Deseño. Vigo: A Nosa Terra.

Tato Fontaíña, Laura (1999): Historia do teatro galego. Vigo: A Nosa Terra.

VieItes, Manuel F. (2005): Historia do Teatro Galego. Unha lectura escénica. A Coruña: Andel, Xunta de Galicia.

\footnotetext{
${ }^{5}$ A do director-escenógrafo é unha das máis prolíficas figuras da creación escénica contemporánea internacional, que podemos exemplificar coa obra de Robert Wilson, Robert Lepage, Jan Fabre, Phillipe Decoufflé, Richard Foreman, etc.
} 
(coord.) (2006): Manuel Lugrís Freire. Do texto ao escenario. Vigo: Galaxia.

(coord.) (2007a): Cento vinte e cinco anos de teatro en galego. Vigo: Galaxia.

(coord.) (2007b): Literatura Dramática Galega. Unha introdución histórica. Vigo: Galaxia.

Xestoso, Manuel (2011): “Falta roña”, Revista Galega de Teatro 67, pp. 51-53.

\section{RECURSOS WEB}

Asociación de Actores e Actrices de Galicia: http://aaag.es.

Centro Dramático Galego: www.centrodramatico.org/cdg/.

Escola Superior de Arte Dramática: www.esadgalicia.com.

Matarile teatro: www.matarileteatro.net.

Rede nasa (Rede virtual de artes vivas e outras leiras): www.redenasa.tv.

Sarabela teatro: www.sarabelateatro.com.

Voadora teatro: www.voadora.es.

${ }^{1}$ Existe una versión autógrafa do poema con algunhas diferenzas textuais, a cal foi incluída no monográfico que a Real Academia Galega publicou co gallo de lle ser dedicado a Varela o Día das Letras Galegas de 2005 ([s. a.] 2005: 60-71). 